\title{
Mycobacterium senegalense tissue infection in a child after fish tank exposure
}

\author{
Rachel Talavlikar $M D^{1}$, Julie Carson $M D^{2}$, Bonnie Meatherill $M D^{3}$, Shalini Desai $M D^{4}$, \\ Meenu Sharma PhD ${ }^{5,6}$, Cary Shandro BSc ${ }^{7}$, Gregory J Tyrrell PhD ${ }^{7}$, Susan Kuhn MD $^{3,8}$
}

R Talavlikar, J Carson, B Meatherill, et al. Mycobacterium senegalense tissue infection in a child after fish tank exposure. Can J Infect Dis Med Microbiol 2011;22(3):101-103.

The present report describes the first known case of an otherwise healthy child who developed a soft tissue infection due to Mycobacterium senegalense - a pathogen usually found in east Africa that is responsible for infecting various animals. The patient presented with nonhealing wounds after sustaining facial lacerations from the shattered glass of a fish tank. The patient responded well to scar revision and antibiotics, with no subsequent relapse.

Key Words: Fish tank; M senegalense; Pediatric; Soft tissue infection

\section{Une infection des tissus mous par le Mycobacterium senegalense chez un enfant exposé à un aquarium}

\begin{abstract}
Le présent rapport décrit le premier cas connu d'un enfant qui a contracté une infection des tissus mous causée par le Mycobacterium senegalense, un pathogène qu'on trouve généralement en Afrique de l'Est et qui infecte divers animaux. Le patient a consulté en raison de lacérations au visage qui ne guérissaient pas, causées par le verre brisé d'un aquarium. Le patient a bien réagi à la révision des cicatrices et aux antibiotiques et n'a pas subi de récidive.
\end{abstract}

ycobacterium senegalense is a rapidly growing Mycobacterium spe$\mathrm{I}_{\text {cies, and has been reported to cause disease among cattle in east }}$ Africa (1). Rare human cases have been reported, but only in adults who were immunosuppressed and had other underlying medical conditions (2-4). We report an otherwise healthy child who developed an $\mathrm{M}$ senegalense soft tissue infection after suffering trauma from the shattered glass of a fish tank.

\section{CASE PRESENTATION}

A healthy three-year-old girl with no previous history of serious illness or hospitalizations presented to a local urgent care centre with multiple facial lacerations. While playing, she had pulled a fish tank containing several live freshwater fish, as well as multiple plastic plants and ceramic ornaments, down from a shelf. The fish tank glass had shattered causing three lacerations on her left cheek. The wounds were cleaned, and a combination of sutures and steri-strips were used to close them. No antibiotics were prescribed.

Two weeks after the injury, the lacerations had not healed and appeared indurated, reddened and thickened with elevated ridges. She was referred to a plastic surgeon, and all three scars were revised. Excision revealed prominent exudative material and granulation tissue under pressure. Swabs were sent for microbiological testing, but not for histopathology or cytopathology. No antibiotics were administered at that time.

The laboratory reported that acid-fast bacilli were observed in the direct specimen smear using fluorescent auramine rhodamine stain. After three days of incubation, growth was detected using the BD BACTEC 960 automated system (BD Diagnostic Systems, USA). An acid-fast organism was visualized growing in the BACTEC MGIT medium (BD Diagnostic Systems) using Ziehl-Neelsen stain. Initial appearance of the organism on subculture was a smooth, nonpigmented, rapidly growing acid-fast organism, which grew optimally at $37^{\circ} \mathrm{C}$ (range $25^{\circ} \mathrm{C}$ to $42^{\circ} \mathrm{C}$, with rougher morphology appearing at lower temperatures). The organism was found to be positive for threeday arylsulfatase, nitrate, growth on MacConkey without crystal violet, iron uptake, and fructose and mannitol use. The isolate did not use arabinose or inositol. Based on these microbiological results, the isolate was sent to the National Reference Centre for Mycobacteriology, National Microbiology Laboratory (Winnipeg, Manitoba) for sequence-based species identification.

Sequencing of the $16 \mathrm{~S}$ ribosomal RNA gene was performed using the following methodology. Crude DNA was extracted using a previously described method (5). Briefly, the tubes containing the culture, buffer and silicon beads were boiled for $10 \mathrm{~min}$ and sonicated for $15 \mathrm{~min}$ at $35 \mathrm{kHz}$. The lysis tubes were then spun at $12,000 \mathrm{rpm}$ for 2 min. All 16S ribosomal RNA polymerase chain reactions were performed using a previously described method (6). The sequencing was performed on the ABI 3730XL sequencer (Applied Biosystems, USA) using a combination of universal primers to sequence the gene. The sequences were edited using Seqman Pro version 8.1.2 (DNASTAR Inc, USA), and analyzed using BioNumerics version 4.5 (Applied Maths Inc, USA). Sequences obtained were compared with a qualitycontrolled sequence database of Mycobacterium type strains and other published strains in the Genbank database (National Institutes of Health, USA) (6). Using a combination of $16 \mathrm{~S}$ gene sequencing and biochemical testing results (Table 1), the patient's isolate was identified as $M$ senegalense $(3,6)$.

Susceptibility testing was performed by E-test using the minimum inhibitory concentration (MIC) breakpoints from the Clinical and Laboratory Standards Institute guidelines for the Mycobacterium fortuitum complex because no established guidelines are available specifically for $M$ senegalense (7). In vitro, the organism was susceptible to amikacin (MIC $0.5 \mu \mathrm{g} / \mathrm{mL}$ ), clarithromycin (MIC $0.5 \mu \mathrm{g} / \mathrm{mL}$ ), ciprofloxacin (MIC $0.25 \mu \mathrm{g} / \mathrm{mL}$ ), doxycycline (MIC $0.25 \mu \mathrm{g} / \mathrm{mL}$ ), cefoxitin (MIC $8 \mu \mathrm{g} / \mathrm{mL}$ ), imipenem (MIC $2 \mu \mathrm{g} / \mathrm{mL}$ ) and trimethoprim/ sulfamethoxazole (MIC $0.5 / 8.5 \mu \mathrm{g} / \mathrm{mL}$ ), which are consistent with previously published results $(3,8)$.

The child was referred to a pediatric infectious disease consultant once the microbiology results were reported. At that time, discharge

${ }^{1}$ Department of Family Medicine; ${ }^{2}$ Department of Pathology and Laboratory Medicine; ${ }^{3}$ Department of Medicine, University of Calgary, Calgary,

Alberta; ${ }^{4}$ Public Health Agency of Canada; ${ }^{5}$ National Reference Centre for Mycobacteriology, National Microbiology Laboratory, Public

Health Agency of Canada; ${ }^{6}$ University of Manitoba, Winnipeg, Manitoba; ${ }^{7}$ Provincial Laboratory for Public Health, ${ }^{8}$ Department of

Pediatrics, University of Calgary, Calgary, Alberta

Correspondence: Dr Susan Kuhn, Department of Pediatrics, Alberta Children's Hospital, 2888 Shaganappi Trail Northwest, Calgary,

Alberta T3B 6A8. Telephone 403-943-7813, fax 403-943-7649, e-mail susan.kuhn@calgaryhealthregion.ca 
TABLE 1

Summary of key phenotypic characteristics of Mycobacterium senegalense, Mycobacterium conceptionense and other closely related Mycobacterium species

\begin{tabular}{|c|c|c|c|c|c|c|c|}
\hline & Patient isolate & M senegalense & M conceptionense & $\begin{array}{c}\text { Mycobacterium } \\
\text { fortuitum }\end{array}$ & $\begin{array}{c}\text { Mycobacterium } \\
\text { porcinum }\end{array}$ & $\begin{array}{c}\text { Mycobacterium } \\
\text { houstonense }\end{array}$ & $\begin{array}{l}\text { Mycobacterium } \\
\text { neworleansense }\end{array}$ \\
\hline Arylsulfatase at three days & + & + & + & + & + & + & + \\
\hline Nitrate reduction & + & + & + & + & - & + & + \\
\hline Iron uptake & + & + & + & + & + & + & + \\
\hline Growth at $42^{\circ} \mathrm{C}$ & $+^{*}$ & $++^{\dagger}$ & $-\ddagger$ & + & + & + & - \\
\hline \multicolumn{8}{|c|}{ Carbon use and oxidative acid production from the following: } \\
\hline Arabinose & - & - & - & + & - & - & - \\
\hline Inositol & - & - & + & - & + & + & + \\
\hline Mannitol & + & + & - & - & + & + & + \\
\hline
\end{tabular}

*Optimal growth temperature: $37^{\circ} \mathrm{C}$; ${ }^{\dagger}$ Optimal growth temperature: $37^{\circ} \mathrm{C}$; ${ }^{\ddagger}$ Optimal growth temperature: $30^{\circ} \mathrm{C}$. Adapted from references $3,8,13$ and 14

persisted from the most inferior scar, however, with minimal erythema and without evidence of regional lymphadenopathy or systemic symptoms such as fever. The patient was started on a combination of clarithromycin, trimethoprim/sulfamethoxazole and ciprofloxacin.

One month after the initiation of therapy, the drainage had stopped. All lesions were closed and well healed by three months, and treatment was discontinued. On subsequent follow-up at two months post-treatment, there was no evidence of relapse.

\section{DISCUSSION}

The present case represents the first known M senegalense-associated infection in an immunologically normal pediatric host. The majority of soft tissue infections in children are caused by Streptococcus pyogenes or Staphylococcus aureus, although in this setting - injury from a fish tank source-Mycobacterium marinum has previously been reported (9).

M senegalense has classically been associated with bovine farcy in east and central Africa, affecting zebu cattle in Chad, Nigeria, Senegal, Somalia and Sudan (1). Since it was first described in 1973 by Chamoiseau (14), M senegalense has rarely been reported. This is most likely due to the placement of $M$ senegalense in the $M$ fortuitum complex (M fortuitum, Mycobacterium peregrinum, Mycobacterium mucogenicum, Mycobacterium mageritense, Mycobacterium farcinogenes, Mycobacterium septicum and the recently described members of the third biovariant Mycobacterium porcinum, Mycobacterium boenickei, Mycobacterium neworleansense, Mycobacterium houstonenense, Mycobacterium conceptionense and Mycobacterium brisbanense) (2). Also, the $M$ senegalense $16 \mathrm{~S}$ ribosomal RNA sequence is nearly identical to that of $M$ farcinogenes, making identification of $M$ senegalense difficult using this method. Others have shown $\mathrm{M}$ senegalense to be a separate, distinct species owing to individual 16S-23S ribosomal DNA internal transcribed spacer sequences (1), and it has been differentiated from $M$ farcinogenes based on its biochemical activity, growth rate and DNA homology (2). In 2005, it was reported that Mycobacterium peregrinum type II, previously classified as an isolate of M peregrinum, is actually a human strain of the bovine pathogen $M$ senegalense (3).

$M$ conceptionense is a recently described species of the $M$ fortuitum complex (8) and can be differentiated from $M$ senegalense due to its different biochemical activity and growth characteristics (Table 1). A combination of carbohydrate utilization tests and molecular studies enable laboratories to accurately identify closely related, rapidly growing mycobacteria species (10).

Advances in molecular identification and its recognition as a human pathogen has led to an increasing, yet limited number of cases of $M$ senegalense infection being reported. The first human case described in 2005 was a catheter-related hematological infection in a 49-year-old woman with non-Hodgkin's lymphoma in Korea (2). In North America, other cases described to date have also occurred in patients who were immunocompromised or sustained soft tissue injury, such as surgery or trauma $(3,4)$, with sites of infection including bone, soft tissue and long-term intravascular catheters.
Unlike many of the previously reported cases of $M$ senegalense, our patient was fully immunized with no history of underlying illness or immune suppression. In addition, she had no known ill contacts, had not been exposed to farm animals or livestock, and had not travelled recently. Despite the infection being located on the head, she did not have associated cervical lymphadenitis, which is the most common presentation of atypical mycobacterial infection in healthy North American children (11).

While members of the $M$ fortuitum complex are recognized as environmental pathogens (found in water and soil), no clear habitat for human strains of $\mathrm{M}$ senegalense outside of Africa has been reported. It is not clear how our patient's lacerations became infected with M senegalense, but presumably it was present in the freshwater or the fish in the broken tank. The specific number, type or origin of the fish and exact contact between the fish and child at the time of injury are not known. The water was discarded at the time that the tank shattered; therefore, testing was not possible. We were not able to identify previous reports of $M$ senegalense associated with aquatic life forms; however, other members of the $M$ fortuitum complex have been associated with infections in fish (12), including aquarium fish, such as goldfish and Siamese fighting fish. Similar to the present case, in these reports, no clear source of the organism was identified. Because other closely related members of the $M$ fortuitum complex have been associated with fish and water infections, the present case suggests that $M$ senegalense may be found in some aquatic environments as well and, therefore, could cause infections associated with fish and freshwater sources.

Because there has only been limited previous experience with this organism, there were no specific guidelines on the types and duration of pediatric treatment to follow for this specific organism. Therefore, the treatment course was based on the limited literature pertaining to M senegalense, literature for similar mycobacterial species and clinical response. Combination antimicrobials, together with surgical debridement, were curative in the present case.

The present case is a reminder that a wide range of atypical mycobacteria, including $M$ senegalense, may be encountered as an etiology of soft tissue infections from unusual exposures such as from a fish tank. $M$ senegalense may be an occasional cause of human infections in otherwise healthy and immunocompromised individuals, and appears to have broad antimicrobial susceptibilities.

\section{REFERENCES}

1. Hamid ME, Roth A, Landt O, Kroppenstedt RM, Goodfellow M, Mauch H. Differentiation between Mycobacterium farcinogenes and Mycobacterium senegalense strains based on 16S-23S ribosomal DNA internal transcribed spacer sequences. J Clin Microbiol 2002;40:707-11.

2. Oh WS, Ko KS, Song JH, et al. Catheter-associated bacteremia by Mycobacterium senegalense in Korea. <www.biomedcentral. com/1471-2334/5/107> (Accessed on June 20, 2011). 
3. Wallace RJ Jr, Brown-Elliot BA, Brown J, et al.

Polyphasic characterization reveals that the human pathogen Mycobacterium peregrinum type II belongs to the bovine pathogen species Mycobacterium senegalense. J Clin Microbiol 2005;43:5925-35.

4. Carson JA, Ahmed-Bentley J, Tyrrell G, Antonation K, Rosser S, Boychuk LR. PICC: The diagnosis. AMMI Canada-CACMID 2008 Annual Conference. Vancouver, February 27 to March 1, 2008.

5. Blackwood KS, Burdz TV, Turenne CY, Sharma MK, Kabani AM, Wolfe JN. Viability testing of material derived from Mycobacterium tuberculosis prior to removal from a containment level-III laboratory as part of a laboratory risk assessment program. BMC Infect Dis 2004;5:4.

6. Turenne CY, Tschetter L, Wolfe J, Kabani A. Necessity of quality-controlled $16 \mathrm{~S}$ rRNA gene sequence databases: Identifying nontuberculous Mycobacterium species. J Clin Microbiol 2001;39:3637-48.

7. Clinical Laboratory and Standards Institute. Susceptibility testing of mycobacteria, nocardiae, and other aerobic actinomycetes. Wayne: CLSI (NCCLS) document M24-A, 2003.

8. Adekambi T, Stein A, Carvajal J, Rault D, Drancourt M. Description of Mycobacterium conceptionense sp. nov., a Mycobacerium fortuitum group organism isolated from a posttraumatic osteitis inflammation. J Clin Microbiol 2006;44:1268-73.
9. Tran H, Kamino H, Walters RF. Mycobacterium marinarum infection. Dermatology Online J 2008;14:7.

10. Brown-Elliot BA, Wallace RJ Jr. Clinical and taxonomic status of pathogenic nonpigmented or late-pigmenting rapidly growing mycobacteria. Clin Microbiol Rev 2002;15:716-46.

11. Burns JL, Malhotra U, Lingappa J, Smith S. Unusual presentations of nontuberculous mycobacterial infections in children. Pediatr Infect Dis 1997;16:802-6.

12. Pourahmad F, Thompson KD, Taggart JB, Adams A, Richards RH. Evaluation of the INNO-LiPA mycobacteria v2 assay for identification of aquatic mycobacteria. J Fish Dis 2008;31:931-40.

13. Schinsky MF, Motry RE, Steigerwalt AG, et al. Taxonomic variation in the Mycobacterium fortuitum third biovariant complex: Description of Mycobacterium boenickei sp. nov., Mycobacterium houstonense sp. nov., Mycobacterium neworleansense sp. nov. and Mycobacterium brisbanense sp. nov. and recognition of Mycobacterium porcinum from human clinical isolates. Int J Syst Evol Microbiol 2004;54:1653-67.

14. Chamoiseau G. Etiology of farcy in African bovines: Nomenclature of the causal organisms Mycobacterium farcinogenes Chamoiseau and Mycobacterium senegalense (Chamoiseau) comb. nov. Int J Syst Bact 1979;29:407-10. 


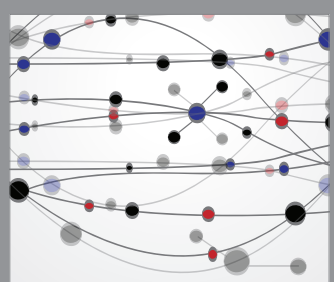

The Scientific World Journal
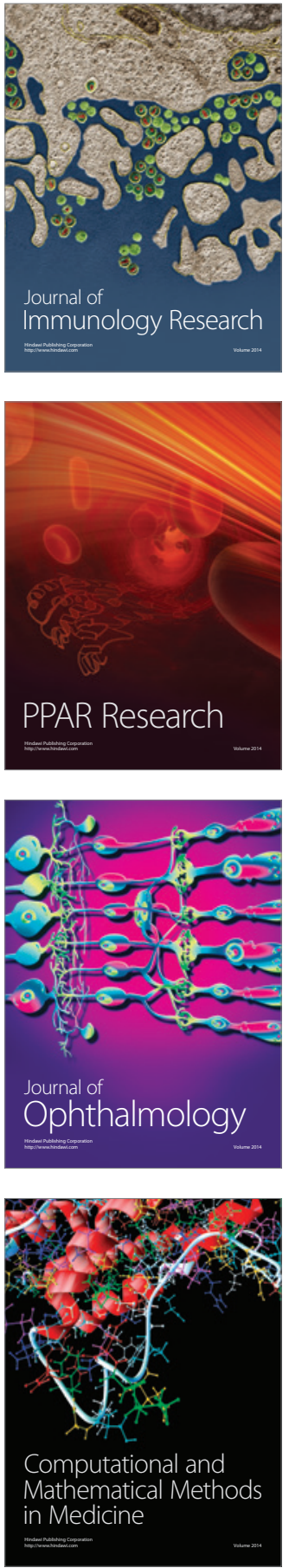

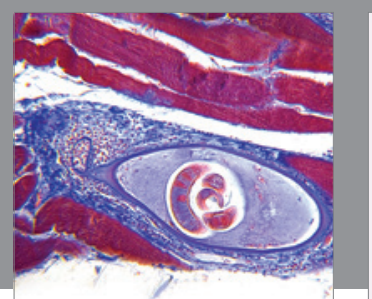

Gastroenterology Research and Practice

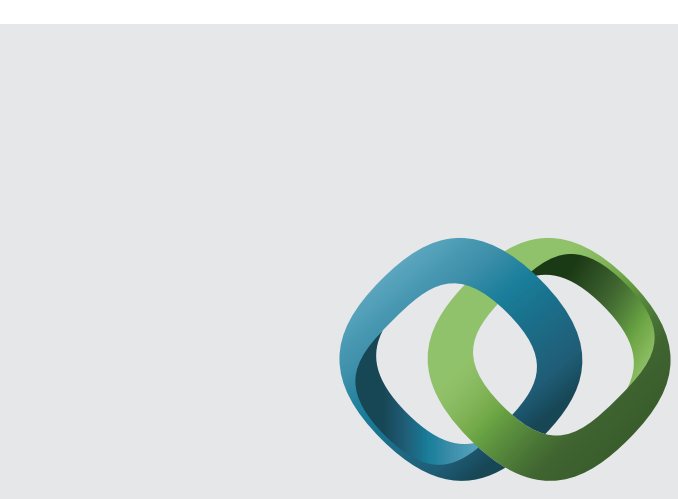

\section{Hindawi}

Submit your manuscripts at

http://www.hindawi.com
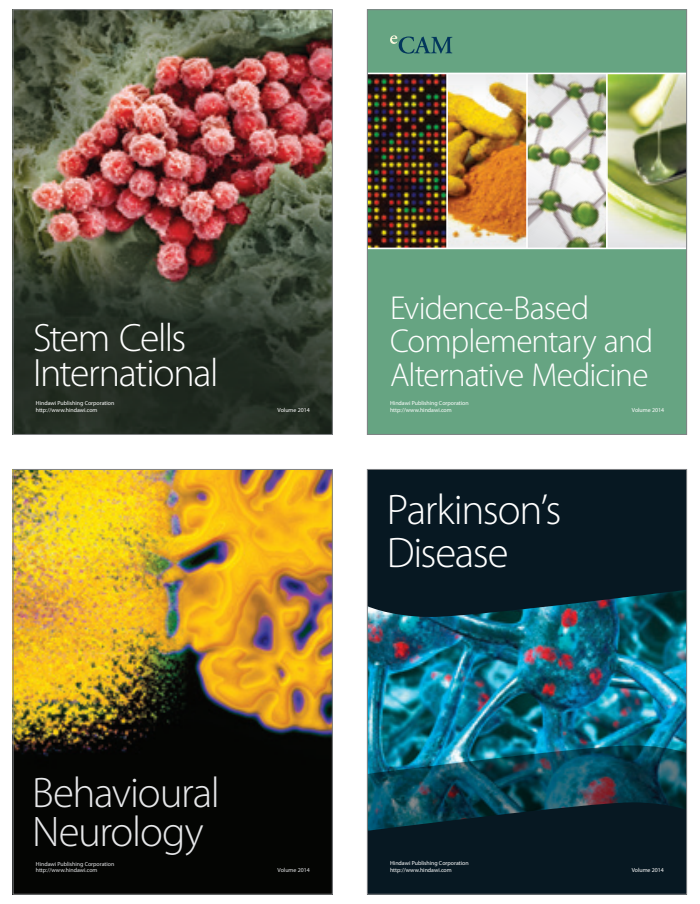
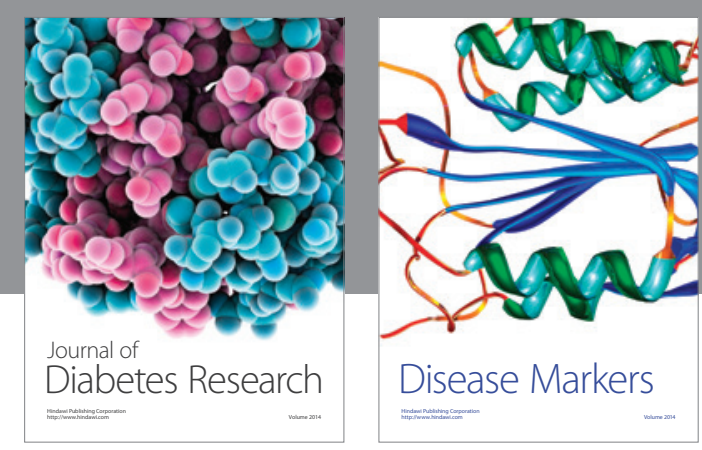

Disease Markers
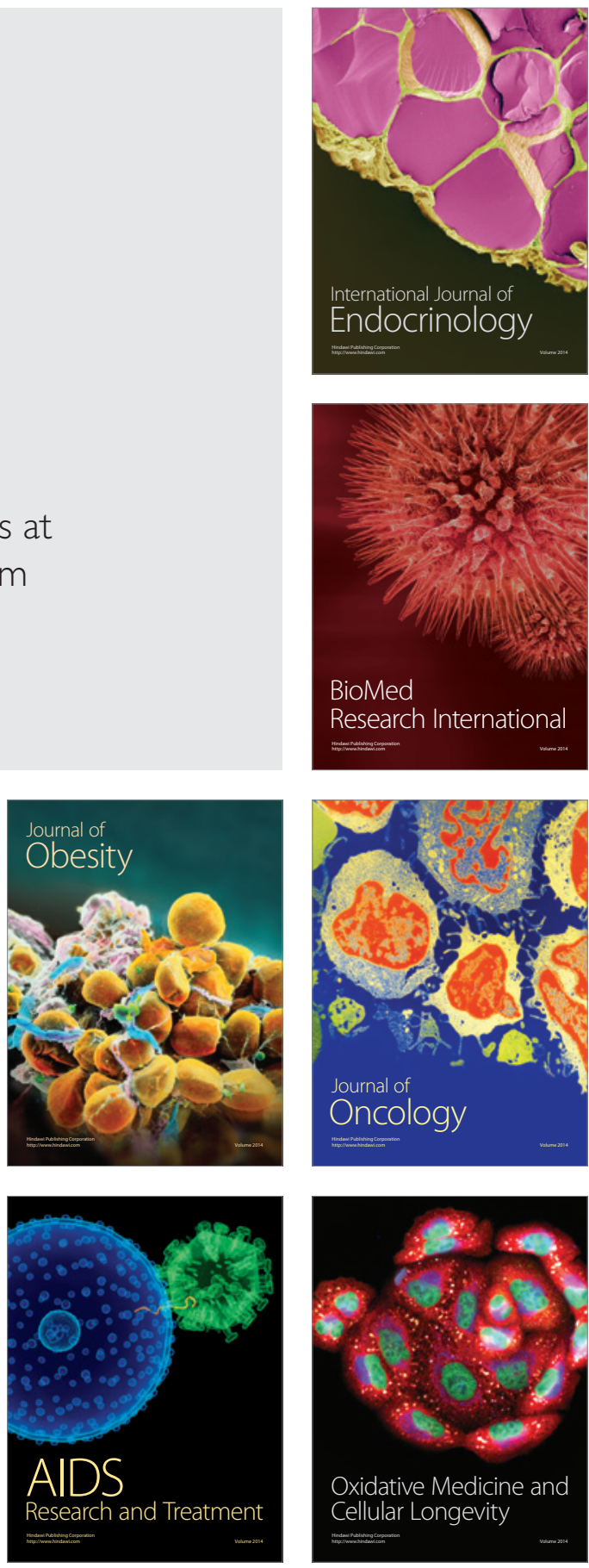